\title{
Investigation of Complement-activating Pattern Recognition Molecules and Associated Enzymes as Possible Inflammatory Markers in Oligoarticular and Systemic Juvenile Idiopathic Arthritis
}

\author{
Christine Petri, Steffen Thiel, Jens Christian Jensenius, and Troels Herlin
}

\begin{abstract}
Objective. The complement system plays a crucial role in the pathogenesis of inflammatory processes. The lectin pathway of the complement system is activated through the recognition of pathogens by soluble pattern recognition molecules (PRM), i.e., mannan-binding lectin (MBL), collectin-LK, and the ficolins. PRM are reportedly correlated to disease activity in rheumatoid arthritis (RA). The aim was to evaluate the pathogenic role of PRM in juvenile idiopathic arthritis (JIA).

Methods. We measured MBL, M-ficolin, H-ficolin, MBL-associated serine proteases (MASP) 1, MASP-2, MASP-3, and 2 alternative splice products, MBL-associated protein (MAp) 44 and MAp19, in plasma and synovial fluid (SF) of children with persistent oligoarticular $(n=109$ in plasma, $n=38$ in SF) and systemic JIA ( $\mathrm{n}=19$ in plasma, $\mathrm{n}=11$ in SF). The concentrations of the proteins were measured by in-house time-resolved immunofluorometric assays.

Results. We observed significantly higher levels of M-ficolin, MASP-1, MASP-2, and MASP-3 in plasma and SF from patients with systemic JIA compared with persistent oligoarticular JIA ( $p<0.001)$. In paired samples of plasma and SF from 47 patients with oligoarticular and systemic JIA, we observed higher concentrations in plasma for both subtypes for 7 of the measured proteins while the reverse relationship was observed for MASP-3. M-ficolin and MASP-2 correlated to erythrocyte sedimentation rate, $\mathrm{C}$-reactive protein, white blood cell count, and platelet count $(\mathrm{p}<0.001)$. M-ficolin was in addition related to the number of active joints and inversely related to hemoglobin levels.

Conclusion. Our results point to plasma M-ficolin and MASP-2 as inflammatory markers in JIA. The levels of all proteins are higher in plasma than in SF, except for MASP-3, indicating that MASP-3 may be produced locally in joints. (First Release June 1 2015; J Rheumatol 2015;42:1252-8; doi:10.3899/jrheum.141449)
\end{abstract}

\section{Key Indexing Terms:}

\section{JUVENILE IDIOPATHIC ARTHRITIS LECTIN FICOLIN COMPLEMENT BIOMARKER}

Juvenile idiopathic arthritis (JIA) is the most common cause of chronic arthritis in childhood with a reported annual incidence of 14-15 per 100,000 children in population-based studies $^{1,2}$. JIA is defined as arthritis lasting more than 6 weeks in a child before the age of 16 years in the absence of any known cause. It is not a single disease entity, but is composed of different subtypes of chronic arthritides in children ${ }^{3}$ and is classified according to the International League of

From the Department of Pediatrics and Department of Biomedicine, Aarhus University Hospital, Aarhus, Denmark.

Supported by the Danish Council for Independent Research, Medical Sciences, the Lundbeck Foundation, the Novo-Nordisk Foundation, the Danish Rheumatism Association, Maria Dorthea and Holger From, the Haderslev Foundation, and the Dagmar Marshall foundation.

C. Petri, MD, Department of Pediatrics and Department of Biomedicine, Aarhus University Hospital; S. Thiel, MD, DMSc; J.C. Jensenius, MD, DMSc, Department of Biomedicine, Aarhus University Hospital; T. Herlin, MD, DMSc, Department of Pediatrics, Aarhus University Hospital.

Address correspondence to Dr. T. Herlin, Pediatric Rheumatology Clinic, Department of Pediatrics, Aarhus University Hospital, DK-8000 Aarhus C,Denmark.E-mail:troeherl@rm.dk

Accepted for publication March 24, 2015.
Associations for Rheumatology (ILAR) based on the onset of the disease $\mathrm{e}^{1,2}$.

Persistent oligoarticular JIA is the most common and generally the mildest subtype. It is defined as arthritis affecting 1-4 joints during the first 6 months of the disease and no more than 4 joints throughout the disease course. Systemic JIA is regarded as one of the most severe subtypes of JIA. It is defined as arthritis in 1 or more joints with or preceded by fever of at least 2 weeks duration that is documented to be daily ("quotidian") for at least 3 days, and accompanied by at least 1 of the following: erythematous rash, generalized lymph node enlargement, hepatomegaly and/or splenomegaly, and serositis ${ }^{3}$.

The pathogenesis of JIA is currently not clearly understood, but is considered to be a result of immune dysregulation because of interactions between genetic and environmental factors ${ }^{4}$. The innate immune system, in particular the complement system, plays a crucial role in the pathogenesis of various inflammatory processes ${ }^{5}$, and has been implicated in rheumatoid arthritis (RA) ${ }^{6}$.

Activation of the complement system may occur through

Personal non-commercial use only. The Journal of Rheumatology Copyright $\odot$ 2015. All rights reserved 
the recognition by $\mathrm{C} 1 \mathrm{q}$ of clusters of antibodies (the classical pathway) or by spontaneous deposition and enhancement on certain surfaces (alternative pathway) or through the lectin pathway ${ }^{7}$. The latter pathway is activated through the recognition of pathogens or altered self-structures by 1 or more of the soluble pattern recognition molecules (PRM), the collectins [mannan-binding lectin (MBL) and collectin-LK, or the ficolins (M-, H-, and L-ficolin) $]^{8,9}$. These PRM are germline-encoded proteins that recognize carbohydrate or acetylated pathogen-associated molecular patterns, present on the surface of intruding pathogens or on altered self-surfaces ${ }^{10}$. Three different MBL-associated serine proteases (MASP; MASP-1, -2, and -3) as well as 2 non-enzymatic MBL-associated proteins (Maps; MAp19 and MAp44) are found in association with MBL and the ficolins. MASP-1 is activated when the PRM/MASP complexes cluster on pathogen surfaces ${ }^{11}$. MASP-1 will cleave and activate MASP-2, which subsequently cleaves $\mathrm{C} 4$ and $\mathrm{C} 2$, and leads to the generation of $\mathrm{C} 3$ convertases and subsequently $\mathrm{C} 5$ convertases and thus inflammatory reactions ${ }^{12}$.

The possible role of the lectin pathway in RA has been investigated. Ammitzbøll, et al detected higher plasma levels of lectin pathway proteins in RA compared with osteoarthritis $(\mathrm{OA})$. Notably higher protein levels were seen in plasma compared with synovial fluid (SF) and significant correlation between plasma M-ficolin and peripheral blood neutrophil counts was found ${ }^{13}$. In a randomized double-blind placebo-controlled trial (OPtimized treatment algorithm in Early Rheumatoid Arthritis) of methotrexate and/or adalimumab $^{6}$, elevated baseline M-ficolin levels in serum in early RA correlated consistently to disease activity markers, most notably Disease Activity Score in 28 joints (DAS28) and the Stanford Health Assessment Questionnaire (HAQ). Low M-ficolin levels at baseline showed a positive predictive value of $95 \%$ of a DAS28 < 3.2 (low disease activity) after 1 year, irrespective of treatment ${ }^{6}$, that indicates $\mathrm{M}$-ficolin as a prognostic marker of RA. Knowledge regarding the possible role of lectin pathway proteins in JIA is lacking. The aim of our present study was to evaluate the possible pathogenic role of the lectin pathway proteins MBL, ficolins, and associated proteins in patients with JIA through a study of the association of disease activities with protein levels.

\section{MATERIALS AND METHODS}

We measured MBL, M-ficolin, H-ficolin, MASP-1, MASP-2, MASP-3, MAp44, and MAp19 in plasma of 109 children with the oligoarticular JIA persistent subtype and in 19 children with systemic JIA. All patients had arthritis in at least 1 joint at time of investigation. Diagnosis of JIA was based on the revised ILAR criteria ${ }^{3}$. SF samples were aspirated from the knee joints during general anesthesia as a part of an intraarticular corticosteroid treatment on the same day as the withdrawal of plasma samples (38 with oligoarticular and 11 with systemic JIA).

Patient records were assessed to gain a clinical and biochemical characteristic corresponding to the date of the blood sample and SF sample: age (mos), duration of active disease (mos), total white blood cell counts (WBC), neutrophil and platelet counts, hemoglobin $(\mathrm{Hb})$, erythrocyte sedimentation rate (ESR), C-reactive protein (CRP), active joint count, rheumatoid factor, antinuclear antibody (ANA), and HLA-B27 (Table 1).

Blood samples (EDTA-plasma) and SF were obtained at the Pediatric Rheumatology Clinic, Department of Pediatrics, Aarhus University Hospital, Denmark. The investigation was approved by the local ethics committee and carried out according to the Helsinki declaration. All samples were stored at $-80^{\circ} \mathrm{C}$.

The in-house time-resolved immunofluorometric assays (TRIFMA) for measuring the proteins of the lectin pathway in plasma and SF have been described: $\mathrm{MBL}^{14}, \mathrm{M}$-ficolin ${ }^{15}, \mathrm{H}$-ficolin ${ }^{16}$, MASP-1 ${ }^{17}$, MASP-2 ${ }^{18}$, MASP- $3^{17}, \mathrm{MAp}^{1} 9^{19}$, and MAp44 ${ }^{20}$. The principle of the TRIFMA was the same as for the sandwich ELISA, except that time-resolved fluorescence of europium rather than enzyme activity was used for the readout. In brief, for the 8 proteins, microtiter wells were coated with monoclonal antibody, incubated with dilutions of the test samples, then with biotinylated monoclonal antibody, and finally developed with europium-labeled streptavidin. The assay for MASP- $1{ }^{17}$ differed from this setup in being an inhibition assay. The concentrations of the analytes were read from standard curves constructed in parallel. At least 3 quality controls were included on each microtiter plate.

Statistics. Data were entered and analyzed using Predictive Analytics Software version 19 (SPSS). The test for normality of the data distribution was performed by the Kolmogorov-Smirnov 1-sample test. Differences between data from oligoarticular and systemic JIA were compared by the Mann-Whitney $U$ test. For the description of differences between lectin pathway proteins in plasma and SF, a paired Student $t$ test was used. Correlations between the levels of the lectin pathway proteins and markers of disease activity were made by calculating Spearman rank correlation coefficient rho. The level of significance ( $p$ ) was defined as $\leq 0.05$.

\section{RESULTS}

Plasma levels of the lectin pathway proteins. The patients with persistent oligoarticular JIA and those in the systemic JIA group were comparable with regard to age at investigation and disease duration (Table 1). Paraclinical data showed elevated levels of ESR, CRP, WBC, and neutrophil

Table 1. Demographic and paraclinical characteristics of patients with oligoarticular and systemic JIA. All patients were RF-negative and HLA-B27-negative. P value indicates differences between oligoarticular and systemic JIA using Mann-Whitney U test. Values are median (IQR) unless otherwise specified.

\begin{tabular}{lccc}
\hline Characteristics & $\begin{array}{c}\text { Oligoarticular } \\
\text { JIA, } \mathrm{n}=109\end{array}$ & $\begin{array}{c}\text { Systemic } \\
\text { JIA, } \mathrm{n}=19\end{array}$ & $\mathrm{p}$ \\
\hline Female/male (\% females) & $79 / 30(72)$ & $10 / 9(53)$ & 0.030 \\
Age at disease onset, mos & $37(21-85)$ & $71(35-119)$ & 0.066 \\
Disease duration, mos & $11.5(6-31)$ & $7(4-20)$ & 0.264 \\
Active joints, $\mathrm{n}$ & $1(1-2)$ & $3.5(1-4.25)$ & 0.001 \\
ESR, mm/h & $10(6-17)$ & $50(27-65)$ & $<0.001$ \\
$\mathrm{CRP}, \mathrm{mg} / \mathrm{l}$ & $5(5-6.8)$ & $86.6(16-130.2)$ & $<0.001$ \\
WBC $\times 10^{9} / 1$ & $8.3(6.45-9.8)$ & $14.4(9.6-20.7)$ & $<0.001$ \\
NEU, $\times 10^{9} / \mathrm{l}$, mean $\pm \mathrm{SD}$ & $4.27 \pm 2.13$ & $12.53 \pm 8.16$ & $<0.001$ \\
Thrombocytes, $\times 10^{9} / 1$ & $349(289-414)$ & $530(414-691)$ & $<0.001$ \\
Hb, mmol/l & $7.3(6.7-7.6)$ & $6.2(5.4-6.8)$ & $<0.001$ \\
ANA-positive, $\mathrm{n}$ & $58 / 109$ & $4 / 18$ & 0.015 \\
\hline
\end{tabular}

JIA: juvenile idiopathic arthritis; RF: rheumatoid factor; IQR: interquartile range; ESR: erythrocyte sedimentation rate; CRP: C-reactive protein; WBC: white blood cell count; NEU: neutrophils; Hb: hemoglobin; ANA: antinuclear antibodies.

Personal non-commercial use only. The Journal of Rheumatology Copyright (C) 2015. All rights reserved. 
and platelet counts in systemic JIA compared with the persistent oligoarticular subtype (Table 1), indicating a higher inflammatory activity in the systemic JIA. The mean number of active joints was higher in the systemic cohort than in the oligoarticular subgroup, but the difference was not significant. Plasma content of lectin pathway proteins from 109 children with persistent oligoarticular JIA and 19 children with systemic JIA are shown in Table 2. The levels of M-ficolin and MASP-2 were higher in plasma from the patients with systemic JIA than in the patients with oligoarticular JIA, whereas the levels of MASP-1 and MASP-3 were significantly higher in the oligoarticular compared with the systemic JIA subgroup (Table 2). In plasma, the MBL,

Table 2. Plasma levels of lectin pathway proteins from patients with oligoarticular and systemic JIA. P value indicates differences between oligoarticular and systemic JIA using Mann-Whitney U test. Values are median (IQR) unless otherwise specified.

\begin{tabular}{lccc}
\hline Variables & $\begin{array}{c}\text { Oligoarticular, } \\
\mu \mathrm{g} / \mathrm{ml}, \mathrm{n}=109\end{array}$ & $\begin{array}{c}\text { Systemic, } \\
\mu \mathrm{g} / \mathrm{ml}, \mathrm{n}=19\end{array}$ & $\begin{array}{c}\text { Oligoarticular } \\
\text { vs Systemic, } \mathrm{p}\end{array}$ \\
\hline MBL & $2.05(0.46-3.63)$ & $1.51(0.49-4.87)$ & $\mathrm{NS}$ \\
M-ficolin & $1.77(1.37-2.39)$ & $3.92(2.48-5.80)$ & $<0.001$ \\
H-ficolin & $22.46(19.74-26.78)$ & $23.92(21.96-33.17)$ & $\mathrm{NS}$ \\
MASP-1 & $13.58(10.42-17.89)$ & $7.84(5.60-9.60)$ & $<0.001$ \\
MASP-2 & $0.33(0.26-0.47)$ & $0.52(0.38-0.70)$ & 0.002 \\
MASP-3 & $4.23(3.54-5.33)$ & $2.72(2.50-3.58)$ & $<0.001$ \\
MAp19 & $0.33(0.24-0.41)$ & $0.40(0.23-0.54)$ & $\mathrm{NS}$ \\
MAp44 & $2.06(1.74-2.46)$ & $2.14(1.86-2.47)$ & $\mathrm{NS}$ \\
\end{tabular}

JIA: juvenile idiopathic arthritis; IQR: interquartile range; MBL: mannan-binding lectin; MASP: MBL-associated serine proteases; MAp: MBL-associated proteins; NS: nonsignificant.
H-ficolin, MAp19, and MAp44 levels were not significantly different between the 2 groups.

The lectin pathway proteins in $S F$ and the plasma/SF ratio. Content of the proteins from aspirated SF obtained at the same day as the blood samples from 38 children with oligoarticular and 11 with systemic JIA are shown in Table 3. In the SF, we measured significantly higher levels of M-ficolin, $\mathrm{H}$-ficolin, MASP-2, and MAp19 in patients with systemic JIA compared with the patients with oligoarticular JIA (data not shown). Paired comparison of SF and plasma concentration of the lectin pathway proteins showed significantly higher concentrations in plasma than in SF, corresponding to a plasma/SF ratio $>1$ for both subtypes, except for MASP-3 (Table 3, Figure 1). Conversely, for MASP-3, we observed a significantly higher concentration in SF than in plasma. For MASP-3, the median plasma/SF ratio was 0.61 and 0.30 for the persistent oligoarticular and the systemic subtype, respectively (Table 3).

Correlation between inflammatory markers and lectin pathway proteins. M-ficolin and MASP-2 were positively related to ESR, CRP, WBC, and neutrophil and platelet count $(\mathrm{p}<0.001$, Table 4$)$. In addition, $\mathrm{M}$-ficolin was positively related to the number of active joints $(\mathrm{p}=0.008)$ and conversely related to $\mathrm{Hb}$ levels (Table 4 ). $\mathrm{H}$-ficolin was also correlated to ESR and CRP, but not to the peripheral blood cell counts. On the other hand, MASP-1 and -3 were negatively correlated to ESR and CRP. MBL as well as MAp19 and MAp44 were not related to the inflammatory markers (Table 4). The results of the hierarchical regression analysis with joint activity as a dependent variable are shown in Table 5. ESR explained $22.8 \%$ of the variance, $\mathrm{M}$-ficolin

Table 3. Ratio between plasma and SF concentration of lectin pathway proteins. T was calculated using a paired Student t test. Values are given as median (IQR) unless otherwise specified.

\begin{tabular}{|c|c|c|c|c|c|c|}
\hline Variables & Plasma, $\mu \mathrm{g} / \mathrm{ml}$ & $\mathrm{SF}, \mu \mathrm{g} / \mathrm{ml}$ & $\mathrm{n}$ & Plasma/SF Ratio & $\mathrm{t}$ & $\mathrm{p}$ \\
\hline \multicolumn{7}{|c|}{ Oligoarticular JIA } \\
\hline MBL & $2.25(0.60-4.11)$ & $0.87(0.33-1.75)$ & 36 & $2.17(1.68-2.86)$ & 6.9 & $<0.001$ \\
\hline H-ficolin & $21.80(18.27-24.25)$ & $9.48(7.20-13.2)$ & 36 & $2.34(1.67-3.09)$ & 13.6 & $<0.001$ \\
\hline MASP-1 & $14.65(10.90-17.09)$ & $4.35(3.16-6.03)$ & 36 & $3.18(2.01-5.05)$ & 9.0 & $<0.001$ \\
\hline MASP-2 & $0.32(0.25-0.39)$ & $0.11(0.07-0.19)$ & 38 & $2.87(1.86-4.00)$ & 9.3 & $<0.001$ \\
\hline MAp44 & $1.94(1.73-2.32)$ & $1.19(0.89-0.14)$ & 38 & $1.84(1.37-2.26)$ & 6.9 & $<0.001$ \\
\hline \multicolumn{7}{|l|}{ Systemic JIA } \\
\hline MBL & $1.47(0.38-2.64)$ & $0.40(0.04-1.18)$ & 11 & $2.02(1.28-15.9)$ & 1.8 & 0.108 \\
\hline M-ficolin & $4.04(2.50-5.89)$ & $1.34(0.71-2.07)$ & 11 & $3.85(2.14-4.62)$ & 4.7 & 0.001 \\
\hline H-ficolin & $24.45(22.38-33.17)$ & $17.76(14.42-22.94)$ & 11 & $1.43(1.07-2.23)$ & 2.3 & 0.042 \\
\hline MASP-1 & $6.86(5.53-8.96)$ & $3.96(2.26-4.83)$ & 9 & $2.12(1.48-3.62)$ & 5.9 & $<0.001$ \\
\hline
\end{tabular}

SF: synovial fluid; IQR: interquartile range; JIA: juvenile idiopathic arthritis; MBL: mannan-binding lectin; MASP: MBL-associated serine proteases; MAp: MBL-associated proteins. 

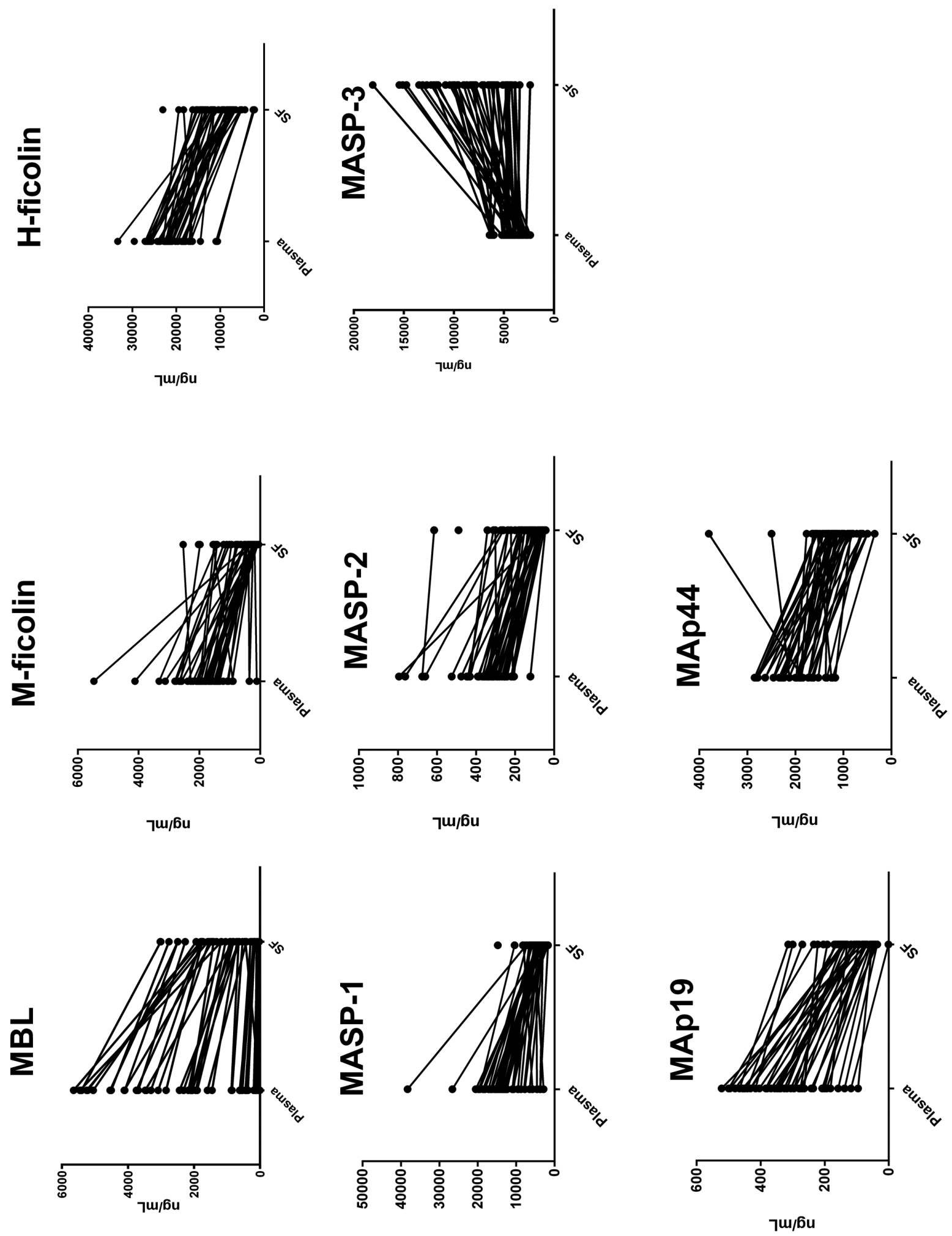

$7 u / 6 u$

Figure 1. Levels of lectin pathway proteins in plasma and SF from patients with oligoarticular and systemic JIA. Values are given as ng/ml. The value for the 2 samples from each individual is connected by a line. SF: synovial fluid; JIA: juvenile idiopathic arthritis; MBL: mannan-binding lectin; MASP: MBL-associated serine proteases; MAp: MBL-associated protein. 
Table 4. Correlation between plasma levels of lectin pathway proteins and inflammatory markers of JIA $(n=128)$. Values are $\mathrm{r}(\mathrm{p}$ value).

\begin{tabular}{lccccccccc}
\hline Variables & MBL & M-ficolin & H-Ficolin & MASP-1 & MASP-2 & MASP-3 & MAp19 & MAp44 & Active Joints \\
\hline Active joints & $-0.112(0.215)$ & $0.236^{*}(0.008)$ & $0.118(0.189)$ & $-0.073(0.419)$ & $0.172(0.056)$ & $-0.124(0.170)$ & $0.011(0.907)$ & $-0.48(0.593)$ \\
ESR & $0.163(0.072)$ & $0.464^{*}(<0.001)$ & $0.214^{*}(0.018)$ & $-0.195^{*}(0.032)$ & $0.347^{*}(<0.001)-0.341^{*}(<0.001)$ & $0.104(0.25)$ & $0.083(0.359)$ & $0.228^{*}(0.011)$ \\
CRP & $0.017(0.852)$ & $0.613^{*}(<0.001)$ & $0.238^{*}(0.008)$ & $-0.244^{*}(0.007)$ & $0.466^{*}(<0.001)$ & $-0.307 *(0.001)$ & $0.088(0.331)$ & $0.128(0.157)$ & $0.325^{*}(<0.001)$ \\
WBC & $0.090(0.32)$ & $0.603^{*}(<0.001)$ & $0.161(0.74)$ & $-0.122(0.177)$ & $0.349^{*}(<0.001)$ & $-0.222^{*}(0.013)$ & $0.085(0.349)$ & $0.122(0.175)$ & $0.216^{*}(0.017)$ \\
NEU & $0.049(0.594)$ & $0.634^{*}(<0.001)$ & $0.150(0.102)$ & $-0.174(0.058)$ & $0.352^{*}(<0.001)$ & $-0.296^{*}(0.001)$ & $0.052(0.569)$ & $0.047(0.611)$ & $0.268^{*}(0.003)$ \\
PLT & $0.042(0.646)$ & $0.376^{*}(<0.001)$ & $0.137(0.134)$ & $-0.143(0.12)$ & $0.493 *(<0.001)$ & $-0.166(0.069)$ & $0.013(0.885)$ & $0.093(0.31)$ & $0.441^{*}(<0.001)$ \\
Hb & $-0.053(0.557)$ & $-0.215^{*}(0.017)$ & $-0.021(0.821)$ & $-0.046(0.617)$ & $-0.171(0.058)$ & $0.228^{*}(0.011)$ & $0.074(0.417)$ & $0.050(0.585)$ & $-0.227 *(0.012)$ \\
\hline
\end{tabular}

* p < 0.05. JIA: juvenile idiopathic arthritis; MBL: mannan-binding lectin; MASP: MBL-associated serine proteases; MAp: MBL-associated proteins; ESR: erythrocyte sedimentation rate; CRP: C-reactive protein; WBC: white blood cell count; NEU: neutrophils; PLT: platelets; Hb: hemoglobin.

Table 5. Hierarchical regression analysis with M-ficolin and other inflammatory markers as variable predictors of the number of active joints.

\begin{tabular}{|c|c|c|c|c|c|c|c|c|c|c|c|}
\hline $\begin{array}{l}\text { Dependent Variable: } \\
\text { Active Joints }\end{array}$ & $\mathrm{n}$ & $\mathrm{r}$ & $\mathrm{p}$ & Step 1 & Step 2 & $\beta$ & $\mathrm{p}$ & Step 1 & Step 2 & $\beta$ & $\mathrm{p}$ \\
\hline ESR & 122 & 0.228 & 0.006 & ESR & & $22.8 \%$ & 0.011 & M-ficolin & & $23.7 \%$ & 0.009 \\
\hline \multirow[t]{2}{*}{ CRP } & 123 & 0.325 & $<0.001$ & CRP & & $28.4 \%$ & $<0.001$ & M-ficolin & & $24.2 \%$ & 0.007 \\
\hline & 123 & 0.242 & 0.004 & & M-ficolin & $6.8 \%$ & 0.534 & & CRP & $28.4 \%$ & 0.010 \\
\hline WBC & 123 & 0.216 & 0.008 & WBC & & $21.6 \%$ & 0.017 & M-ficolin & & $24.2 \%$ & 0.007 \\
\hline
\end{tabular}

ESR: erythrocyte sedimentation rate; CRP: C-reactive protein; WBC: white blood cell count.

explained another $16.7 \%$, but it did not reach significance $(\mathrm{p}=0.095)$. If $\mathrm{M}$-ficolin was entered first, it would explain $23.7 \%$ of the variance $(\mathrm{p}=0.009)$ and ESR would explain an additional $15 \%(\mathrm{p}=0.132)$. However, CRP, but not WBC, seemed to be a better predictor of joint activity than M-ficolin (Table 5).

\section{DISCUSSION}

As far as we know, this is the first study to investigate the possible role of the lectin pathway of complement in JIA. We found a significant difference between the plasma levels of M-ficolin, MASP-1, MASP-2, and MASP-3 in the oligoarticular subtype as compared with the systemic subtype. The levels of M-ficolin and MASP-2 were higher in systemic JIA than in persistent oligoarticular JIA, which presumably was reflecting the increased inflammatory activity in the patients with systemic JIA because these had significantly elevated levels of ESR, CRP, WBC, and neutrophils and platelet counts. However, the study contained only a small sample size of the systemic subtype ( $\mathrm{n}=19)$, which was compared with the larger sample size of the oligoarticular subtype $(n=$ 109). The difference in sample sizes is a natural outcome of the difference in prevalence of these subtypes. The levels of the lectin pathway proteins were also measured in serum from 27 patients with oligoarticular and 9 patients with systemic JIA; we found similar differences between the 2 types of JIA (data not shown). Direct comparison to the plasma levels of the lectin pathway proteins in healthy children has not been made in our study. However, in a previous publication from our research laboratory, the serum levels of MBL, M-ficolin, H-ficolin, and MASP-2 were measured in 91 healthy children between the ages of 1 and 16 years ${ }^{21}$. Although not directly comparable, the median levels were $1.96 \mu \mathrm{g} / \mathrm{ml}$ for MBL, $1.4 \mu \mathrm{g} / \mathrm{ml}$ for M-ficolin, $24.3 \mu \mathrm{g} / \mathrm{ml}$ for $\mathrm{H}$-ficolin, and $0.27 \mu \mathrm{g} / \mathrm{ml}$ for MASP-2, which were in the order of (MBL, H-ficolin) or lower (M-ficolin, MASP-2) than the levels observed for the patients ${ }^{21}$. The remaining proteins have yet to be measured in healthy children.

The plasma and SF levels of MBL, M-ficolin, $\mathrm{H}$-ficolin, MASP-2, and MASP-3 have been measured in patients with $\mathrm{RA}$ and $\mathrm{OA}^{13}$. The plasma levels of $\mathrm{M}$-ficolin in systemic JIA were higher than the levels found in patients with $\mathrm{RA}^{13}$. The level of M-ficolin obtained from patients with oligoarticular JIA was lower than in RA, but still higher than in patients with OA. Conversely, we found higher levels of MASP-1 and MASP-3 in patients with oligoarticular JIA compared with the systemic group. As in the adult study, MASP-3 (MASP-1 was not included here) was measured at higher levels in patients with low inflammatory activity such as the patients with OA, compared with $\mathrm{RA}^{13}$.

Comparison of plasma and SF levels of the lectin pathway proteins showed a general pattern of significantly higher levels in plasma compared with the SF. Because SF is largely an ultra-filtrate of plasma ${ }^{22}$, higher protein concentrations are to be expected in plasma, which has also been previously observed in patients with RA ${ }^{13}$.

Remarkably, for MASP-3, we conversely observed a

Personal non-commercial use only. The Journal of Rheumatology Copyright $@$ 2015. All rights reserved 
significantly higher concentration in SF compared with plasma. This differs from the findings in RA reported by Ammitzbøll, et $a l^{13}$ showing that patients with RA had lower levels of MASP-3 in SF compared with plasma. MASP-3 is encoded by the MASPI gene, as is MASP-1, but whereas MASP-1 is primarily synthesized by the liver, MASP-3 is produced at several $\operatorname{sites}^{23}$. Our observation indicates that MASP-3 is synthesized locally in the joint or actively transported into the joint. In mice, production of MASP-1 and MASP-3 has been observed from synovial adipose tissue and fibroblast-like synoviocytes in knee joints ${ }^{24}$. Whether the difference between RA and JIA MASP-3 plasma/SF ratio is due to pathogenetic differences is unknown.

We found that M-ficolin levels correlated positively with WBC, neutrophils, and ESR, and negatively with $\mathrm{Hb}$ in patients with JIA. Similarly, associations between plasma levels of M-ficolin in patients with RA and leukocytes, neutrophils, and monocytes have been described ${ }^{6}$. The enhanced levels of M-ficolin may result from increased inflammation. It has previously been reported that M-ficolin is synthesized by monocytes and neutrophils ${ }^{25}$, and our findings of a significant correlation between $\mathrm{M}$-ficolin and increased WBC and neutrophils is in accordance with this observation.

A study showed that the level of M-ficolin in plasma reflects disease activity in RA and that low levels of M-ficolin detected early during the disease course predicts remission in patients with $\mathrm{RA}^{6}$. Circulating high levels of M-ficolin levels were associated with a high disease activity in RA, and were associated with numerous disease activity markers in early disease-modifying antirheumatic drugs-naive patients with RA, most notably the DAS28 and $\mathrm{HAQ}^{6}$. Because we found a close correlation between plasma M-ficolin and MASP-2 levels and markers of disease activity, our results indicate a possible association like the one found for patients with RA ${ }^{6}$.

Comparison of the lectin pathway plasma levels for M-ficolin, MASP-1, MASP-2, and MASP-3 revealed significant differences between the oligoarticular and the systemic subtype of JIA. We observed significantly higher levels of lectin pathway proteins in plasma than in SF for both subtypes except for the opposite ratio for MASP-3, indicating that MASP-3 may be secreted into or produced locally in the joint. The levels of M-ficolin and MASP-2 in plasma were closely related to the enhanced degree of inflammation. This leaves M-ficolin and MASP-2 as potential new biomarkers for disease activity in patients with JIA. Further investigations are required to confirm these findings.

\section{ACKNOWLEDGMENT}

We thank Lisbeth Jensen and Annette G. Hansen for expert technical assistance.

\section{REFERENCES}

1. Berntson L, Andersson Gäre B, Fasth A, Herlin T, Kristinsson J, Lahdenne P, et al; Nordic Study Group. Incidence of juvenile idiopathic arthritis in the Nordic countries. A population based study with special reference to the validity of the ILAR and EULAR criteria. J Rheumatol 2003;30:2275-82.

2. Riise ØR, Handeland KS, Cvancarova M, Wathne KO, Nakstad B, Abrahamsen TG, et al. Incidence and characteristics of arthritis in Norwegian children: a population-based study. Pediatrics 2008;121:e299-306.

3. Petty RE, Southwood TR, Manners P, Baum J, Glass DN, Goldenberg J, et al; International League of Associations for Rheumatology. International League of Associations for Rheumatology classification of juvenile idiopathic arthritis: second revision, Edmonton, 2001. J Rheumatol 2004;31:390-2.

4. Prakken B, Albani S, Martini A. Juvenile idiopathic arthritis. Lancet 2011;377:2138-49.

5. Ricklin D, Lambris JD. Complement in immune and inflammatory disorders: pathophysiological mechanisms. J Immunol 2013;190:3831-8

6. Ammitzbøll CG, Thiel S, Jensenius JC, Ellingsen T, Hørslev-Petersen K, Hetland ML, et al. M-ficolin levels reflect disease activity and predict remission in early rheumatoid arthritis. Arthritis Rheum 2013;65:3045-50.

7. Fujita T. Evolution of the lectin-complement pathway and its role in innate immunity. Nat Rev Immunol 2002;2:346-53.

8. Worthley DL, Bardy PG, Mullighan CG. Mannose-binding lectin biology and clinical implications. Intern Med J 2005;35:548-55.

9. Endo Y, Matsushita M, Fujita T. The role of ficolins in the lectin pathway of innate immunity. Int J Biochem Cell Biol 2011; 43:705-12.

10. Janeway CA Jr. Approaching the asymptote? Evolution and revolution in immunology. Cold Spring Harb Symp Quant Biol 1989;54:1-13

11. Degn SE, Kjaer TR, Kidmose RT, Jensen L, Hansen AG, Tekin M, et al. Complement activation by ligand-driven juxtaposition of discrete pattern recognition complexes. Proc Natl Acad Sci USA 2014;111:13445-50.

12. Degn SE, Jensen L, Hansen AG, Duman D, Tekin M, Jensenius JC, et al. Mannan-binding lectin-associated serine protease (MASP)- 1 is crucial for lectin pathway activation in human serum, whereas neither MASP-1 nor MASP-3 is required for alternative pathway function. J Immunol 2012;189:3957-69.

13. Ammitzbøll CG, Thiel S, Ellingsen T, Deleuran B, Jorgensen A, Jensenius JC, et al. Levels of lectin pathway proteins in plasma and synovial fluid of rheumatoid arthritis and osteoarthritis. Rheumatol Int 2012;32:1457-63.

14. Gadjeva M, Steffen Thiel S, Jensenius JC. Assays for mannan binding lectin pathway. In: Coligan JE, editor. Current protocols in immunology. Hoboken: John Wiley \& Sons Ltd; 2004: Chapter 13:Unit 13.6.

15. Wittenborn T, Thiel S, Jensen L, Nielsen HJ, Jensenius JC. Characteristics and biological variations of $\mathrm{M}$-ficolin, a pattern recognition molecule, in plasma. J Innate Immun 2010;2:167-80.

16. Krarup A, Sørensen UB, Matsushita M, Jensenius JC, Thiel S. Effect of capsulation of opportunistic pathogenic bacteria on binding of the pattern recognition molecules mannan-binding lectin, L-ficolin, and H-ficolin. Infec Immun 2005;73:1052-60.

17. Thiel S, Jensen L, Degn SE, Nielsen HJ, Gál P, Dobó J, et al. Mannan-binding lectin (MBL)-associated serine protease-1 (MASP-1), a serine protease associated with humoral pattern-recognition molecules: normal and acute-phase levels in serum and stoichiometry of lectin pathway components. Clin Exp Immunol 2012;169:38-48.

18. Møller-Kristensen M, Jensenius JC, Jensen L, Thielens N, Rossi V, Arlaud G, et al. Levels of mannan-binding lectin-associated serine protease- 2 in healthy individuals. J Immunol Methods $2003 ; 282: 159-67$

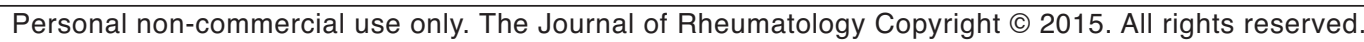


19. Degn SE, Thiel S, Nielsen O, Hansen AG, Steffensen R, Jensenius JC. MAp19, the alternative splice product of the MASP2 gene. J Immunol Methods 2011;373:89-101.

20. Degn SE, Jensen L, Gál P, Dobó J, Holmvad SH, Jensenius JC, et al. Biological variations of MASP-3 and MAp44, two splice products of the MASP1 gene involved in regulation of the complement system. J Immunol Methods 2010;361:37-50.

21. Sallenbach S, Thiel S, Aebi C, Otth M, Bigler S, Jensenius JC, et al. Serum concentrations of lectin-pathway components in healthy neonates, children and adults: mannan-binding lectin (MBL), M-, L-, and H-ficolin, and MBL-associated serine protease-2 (MASP-2). Pediatr Allergy Immunol 2011;22:424-30.

22. McCarty WJ, Luan A, Siddiqui M, Hansen BC, Masuda K, Sah RL. Biomechanical properties of mixtures of blood and synovial fluid. J Orthop Res 2011;29:240-6.
23. Dahl MR, Thiel S, Matsushita M, Fujita T, Willis AC, Christensen T, et al. MASP-3 and its association with distinct complexes of the mannan-binding lectin complement activation pathway. Immunity 2001;15:127-35.

24. Arend WP, Mehta G, Antonioli AH, Takahashi M, Takahashi K, Stahl GL, et al. Roles of adipocytes and fibroblasts in activation of the alternative pathway of complement in inflammatory arthritis in mice. J Immunol 2013;190:6423-33.

25. Schlapbach LJ, Kjaer TR, Thiel S, Mattmann M, Nelle M, Wagner $\mathrm{BP}$, et al. M-ficolin concentrations in cord blood are related to circulating phagocytes and to early-onset sepsis. Pediatr Res 2012;71:368-74. 